\title{
Modifications induced by swift heavy ions
}

\author{
C TRAUTMANN \\ Gesellschaft für Schwerionenforschung, Planckstr. 1, 64291 Darmstadt, Germany
}

\begin{abstract}
On their way through matter, energetic heavy ions induce a continuous trail of ionization and excitation. A narrow path of irreversible physical, chemical and structural changes, the latent track, is formed. In this report, some of the most important techniques (transmission electron and atomic force microscopy, small-angle X-ray scattering, chemical etching) to study and to characterize ion induced modifications will be presented. Furthermore, selected examples for application oriented projects will be given.
\end{abstract}

Keywords. Ion tracks; transmission electron microscopy; scanning force microscopy; small-angle X-ray scattering; track etching.

\section{Introduction}

Tracks of energetic particles in solids have been investigated for more than three decades. In particular, the availability of accelerators for heavy ions and nowadays even for cluster beams promoted a wide variety of systematic track studies using well defined irradiation conditions. The field has continuously developed both in basic understanding and in technological applications (Fleischer et al 1975; Spohr 1990; Fleischer 1998). This paper gives a short review of several techniques presently used to gain a better knowledge of the mechanisms of track formation and of track properties. Recent studies by means of transmission electron and atomic force microscopy, small-angle X-ray scattering and chemical etching are presented. Finally, also some selected examples for new technological applications of etched tracks in polymers are given.

All irradiation experiments have been performed with ions of energies of several $\mathrm{MeV}$ per nucleon $(\mathrm{MeV} / \mathrm{u})$. In this energy regime, the stopping process in matter is dominated by inelastic interactions of the ions with the target electrons (electronic energy loss) whereas elastic collision processes with the target atoms (nuclear energy loss) can be neglected (figure 1).

During the slowing down process, the energy of the fast ions is transformed into excitation, ionization and kinetic energy of ejected target electrons. Most of the primary ionizations and excitations occur close to the ion trajectory in a cylindrical region with a radius of a few nanometers (track core). At larger distances, in the so-called track halo, the ionizations are caused by energetic $\delta$-electrons of secondary cascade processes. The size of the halo depends on the projectile velocity and may reach up to about $1 \mu \mathrm{m}$ (Katz et al 1990; Kraft and Krämer 1993; Gervais and Bouffard 1994). Defects induced in the halo are significant only in materials which are sensitive to radiolysis, such as alkali halides, polymers, or biological objects. The damage creation in this region is similar to processes known from conventional radiation such as gammas, X-rays or electrons.

\section{Imaging of ion tracks}

\subsection{Transmission electron microscopy}

The first direct observation of damage induced by fission fragments in mica was made by Silk and Barnes (1959) using transmission electron microscopy (TEM). During longer periods of observation, however, the damaged areas disappeared due to the annealing effect of the electron beam, making it very difficult to obtain detailed information on the structure of the tracks.

In later years, a significant effort was achieved to observe tracks in various other solids mainly in insulators [ $\mathrm{ZrSiO}_{4}$ (Fleischer et al 1965; Bursill and Braunshausen 1990), $\mathrm{MoO}_{3}$ (Izui and Suzuki 1963) or in semiconducting layered crystals $\mathrm{MoS}_{2}$ (Izui and Fujita 1963; Morgan and Chadderton 1968)]. To date, improved technologies allow the observation of tracks with much higher resolution. Tracks have been imaged in all kinds of other materials [e.g., high $T_{\mathrm{c}}$ superconductors (Bourgault et al 1989a, b; Legris et al 1993; Zhu 1993; Wiesner et al 1996), $\mathrm{SiO}_{2}$ quartz (Meftah et al 1994), yttrium-iron garnet (Fuchs et al 1987; Toulemonde 1988, 1993; Houpert et al 1989a, b; Studer 1991; Dunlop et al 1997), sapphire (Ramos et al 1998)], including even a few selected metals (Barbu et al 1991; Henry et al 1992; Dammak et al 1995a, b). In most non-radiolytic insulators, tracks appear as disordered cylindrical zones as demonstrated for muscovite mica in figure 2 (Vetter et al 1998a). The boundary between the amorphized track region and the crystalline surroundings is extremely sharp. 
Another TEM image is given in figure 3 showing a single track of an uranium ion in germanium sulfide. It is interesting to note that the cross sections of the track is not circular but has an elliptical shape. Their long axes are oriented along the crystal axis with the smallest lattice constant. Obviously, the anisotropy of the GeS lattice is reflected in the resulting track geometry. In addition, the amorphized track core is surrounded by four regions of oriented strain manifested by the dark butterfly shaped contrast in the crystalline material at a distance of about 10-20 nm (Scholz et al 1993; Vetter et al 1994, 1998b; Vetter 1995).

\subsection{Scanning probe microscopy}

Since several years, the technique of scanning tunnelling (STM) and scanning force microscopy (SFM) is applied to investigate ion irradiated surfaces of various solids (Porte et al 1989, 1991; Coratger et al 1990; Kemmer et al 1992a; Yan et al 1994; Biró et al 1995, 1996).

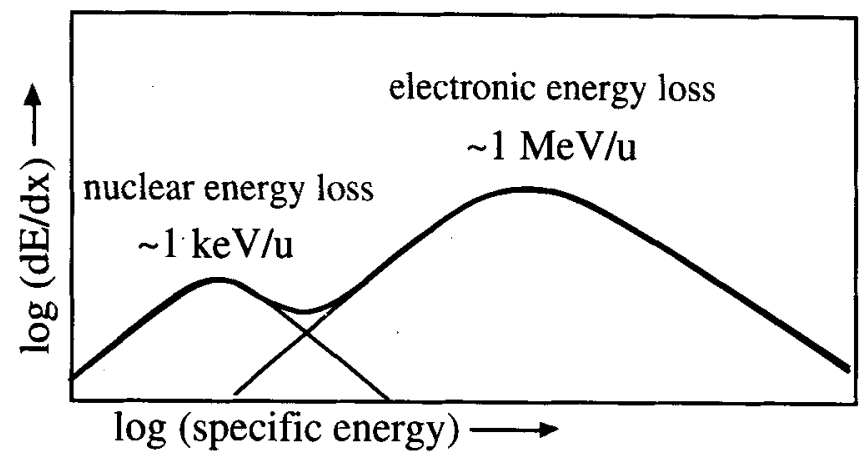

Figure 1. Qualitative relation of nuclear and electronic energy loss as a function of the ion energy.

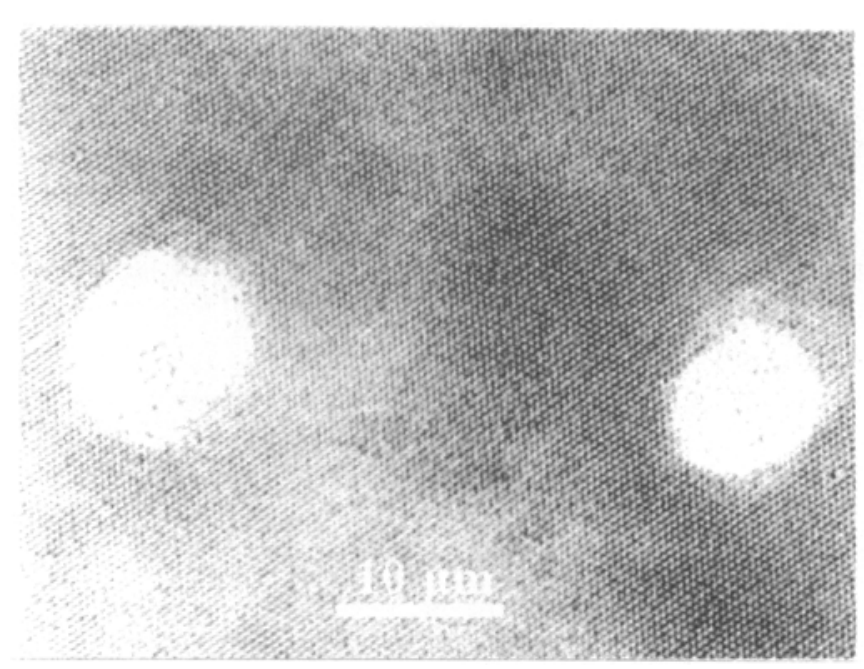

Figure 2. Tracks of $\mathrm{U}$ ions $(11.4 \mathrm{MeV} / \mathrm{u})$ in muscovite mica (Vetter et al 1998a).
A special feature of this technique is the characterization of ion induced modifications on a nanometer scale such as amorphization, modified friction and elasticity (Kemmer et al 1992b; Bouffard et al 1993; Hagen et al 1994a; Neumann et al 1996a). The dynamic friction coefficient of the track zones was analysed quantitatively by simultaneously recording topographical and lateralforce images. For tracks in mica, the coefficient inside the track zone was found to be about a factor of two larger than compared with the virgin material outside the track (Hagen et al 1994b). In order to test changes of the elastic properties, the microscope is operated in a mode where the sample position is varied periodically to the sample surface (figure 4). This results in a periodic

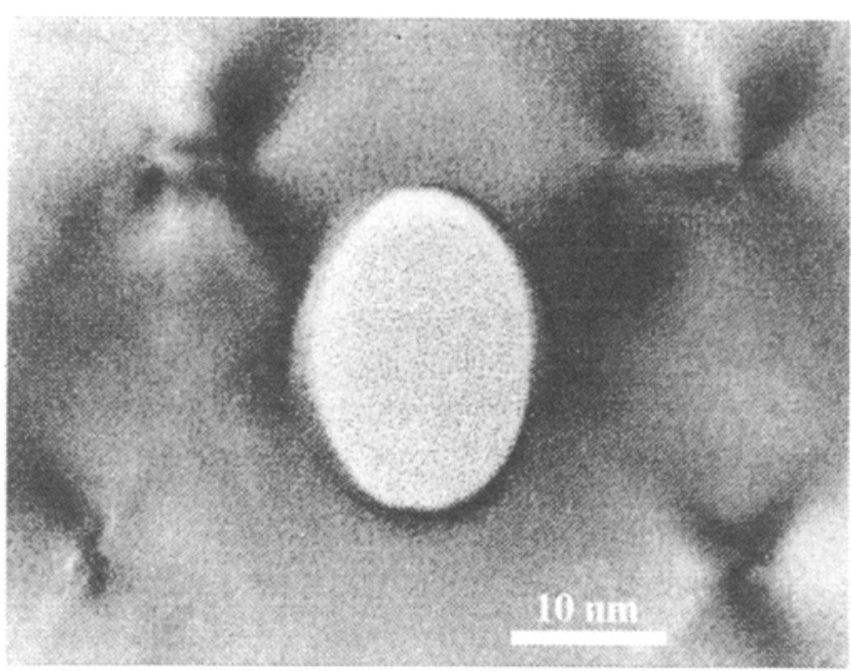

Figure 3. Tracks of $\mathrm{U}$ ions $(11.4 \mathrm{MeV} / \mathrm{u})$ in germanium sulfide irradiated normal to the crystal surface (Vetter et al 1998a).

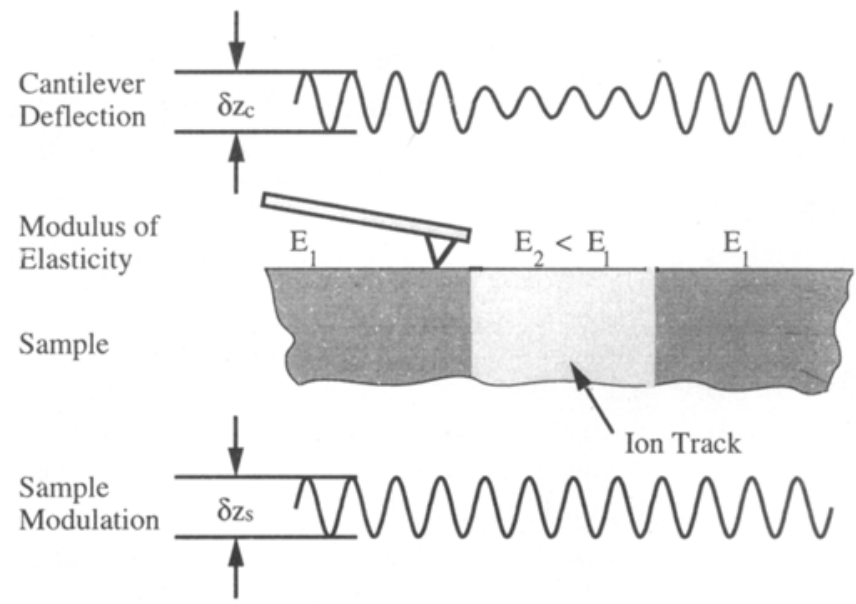

Figure 4. Scheme of the SFM modulation mode. Driven by a sample modulation of constant amplitude, the cantilever is deflected as a function of the surface elasticity (Neumann et al 1996b). 
deformation of the sample surface and in a vertical cantilever deflection. The deflection is enlarged (reduced) if the sensor probes a harder (softer) surface area (Neumann et al 1996b).

The force modulation image of a mica surface irradiated with gold ions is shown in figure 5. The circular dark areas indicate that the track zones have a reduced elasticity. It should be noted that the averaged diameters obtained by force-modulation and by lateral-force imaging are in good agreement.

\section{Small-angle $X$-ray scattering}

Besides the observation of individual ion tracks, it is also possible to use techniques where specific information about many tracks is obtained. Especially diffraction technique using small-angle scattering of X-rays (SAXS) and neutrons was established in the early eighties (Dartyge et al 1981; Albrecht et al 1985, 1986).

A large number of ion tracks (about $10^{10}$ ) act as scattering objects. The change of the electronic (X-rays) or atomic (neutron) density along the tracks results in a highly anisotropic scattering. A typical SAXS set-up is shown in figure 6 . The scattering pattern of a lithium fluoride crystal irradiated with xenon ions is presented in figure 7. Here, the grey scale is a measure of the $\mathrm{X}$-ray intensity recorded by means of a position-sensitive detector. The light spot in the centre originates from the catcher of the primary X-ray beam. The high contrast along the vertical axis of the detector plane originates from the electron density difference of the damage in the tracks compared to the surrounding unirradiated crystal.

For the analysis of the scattered intensity distribution, it is assumed that each track can mathematically be described by a cylinder of a Gaussian radial density variation with the $z$-axis of the cylinder corresponding to the ion trajectory. For such a configuration, the intensity distribution $I\left(k_{\mathrm{r}}, k_{\mathrm{z}}\right)$ in the reciprocal space is given by

$$
I\left(k_{\mathrm{r}}, k_{\mathrm{z}}\right)=\Delta \rho^{2} 4 \pi^{2} a^{4} \sin ^{2}\left(k_{\mathrm{z}} R / 2\right) / k_{\mathrm{z}}^{2} \exp \left(-k_{\mathrm{r}}^{2} a^{2} / 2\right)
$$

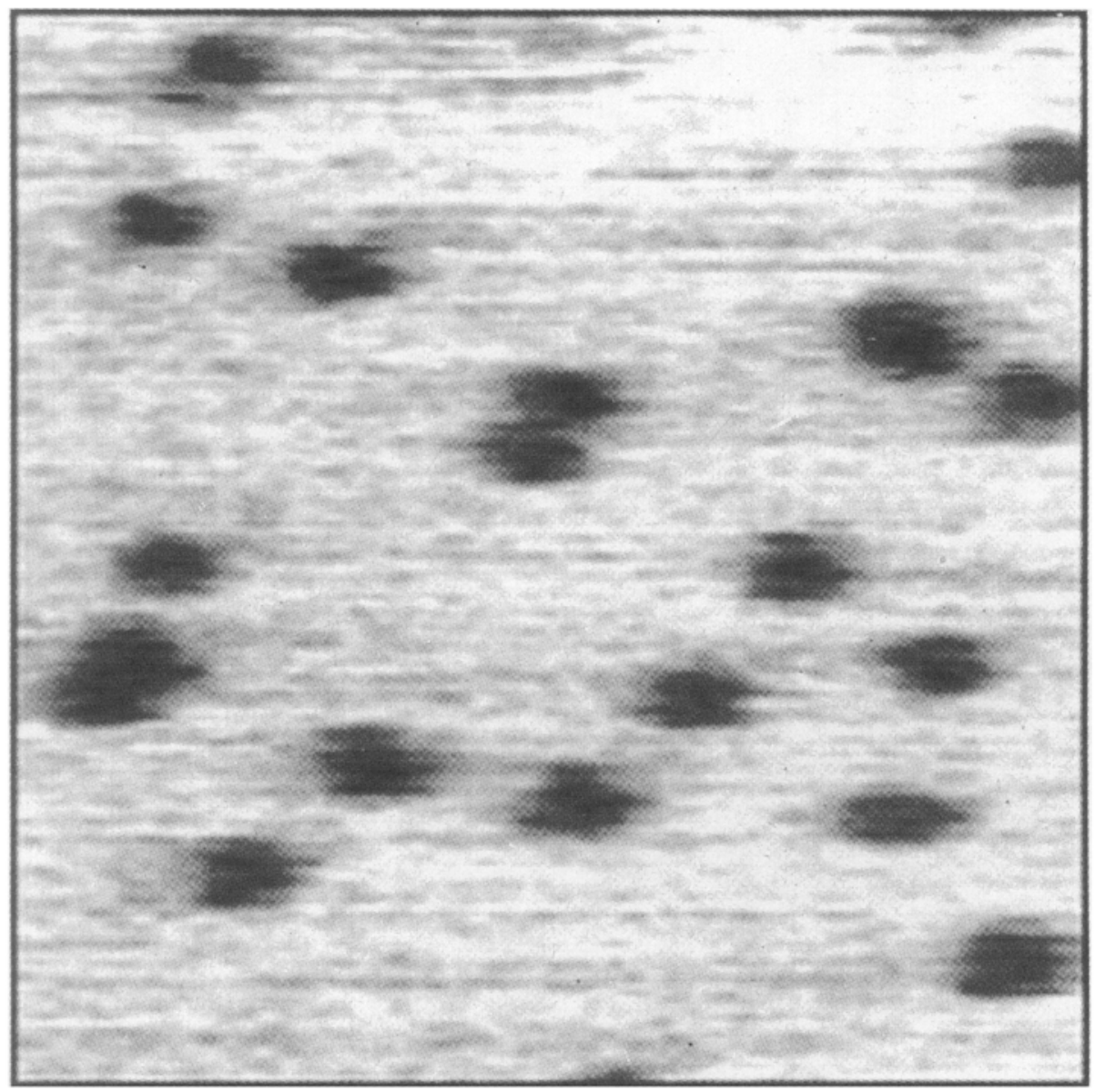

Figure 5. Force-modulation image of a mica surface $(170 \mathrm{~nm} \times 170 \mathrm{~nm})$ irradiated with $\mathrm{Au}$ ions (13.4 MeV/u). The dark impact zones indicate reduced surface elasticity (Neumann et al 1996b). 
where $R$ is the length of the cylindrical track, $k_{\mathrm{z}}$ and $k_{\mathrm{r}}$ the length of the momentum vector, respectively parallel and perpendicular to the ion path. $k_{\mathrm{r}}$ is obtained from the relation $k_{\mathrm{r}}=4 \pi / \lambda \sin \Theta$, where $2 \Theta$ denotes the scattering angle and $\lambda$ the wavelength of the $\mathrm{X}$-ray beam. $\Delta \rho$ is the maximum electron density difference between the damaged material of the track and the virgin crystal, and $a$ defines the Gaussian radius of the track at which $\Delta \rho$ decreases to $1 / e$.

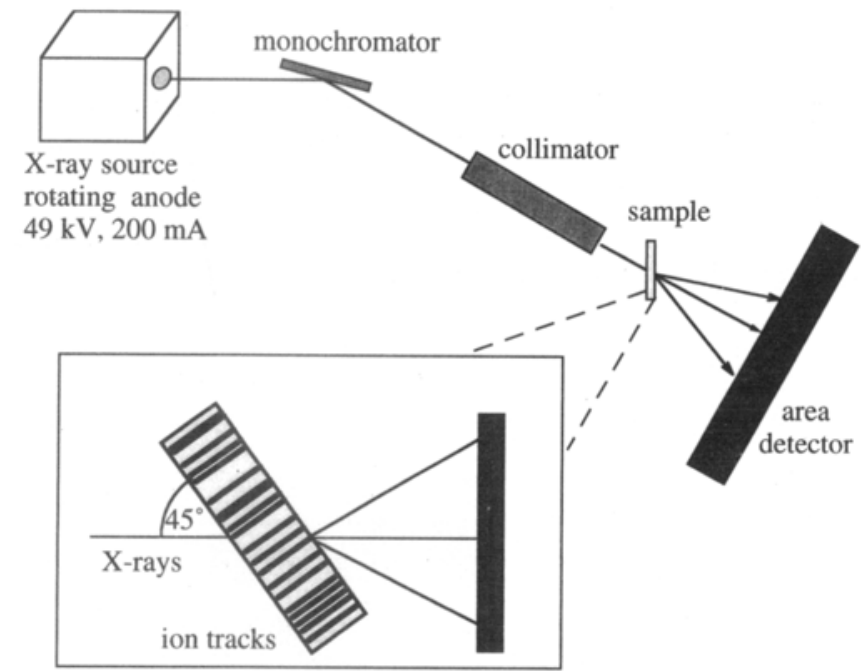

Figure 6. Scheme of SAXS set-up.

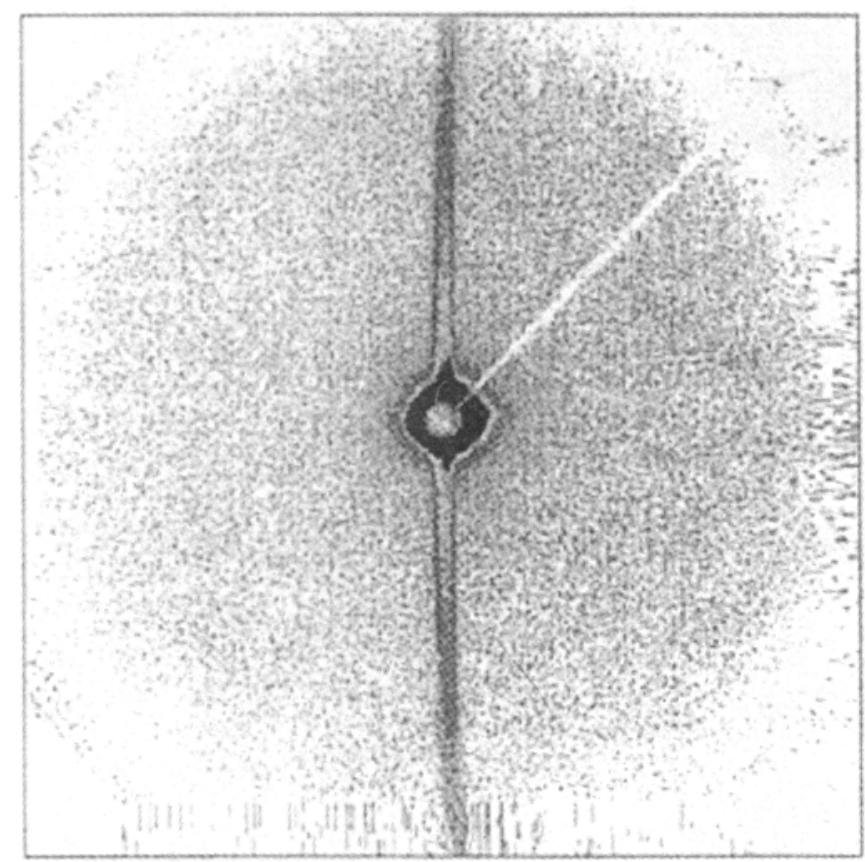

Figure 7. Anisotropic scattering pattern of a lithium fluoride crystal irradiated with $10^{10} \mathrm{Xe}$ ions $/ \mathrm{cm}^{2}(11.4 \mathrm{MeV} / \mathrm{u}$ ) (Schwartz et al 1998).
Using a Guinier plot $\left(\ln \left(I\left(k_{\mathrm{r}}\right)\right)\right.$ vs $\left.\left(k_{\mathrm{r}}\right)^{2}\right)$, the Gaussian track radius can be determined from the slope of a straight line fitted to the data. Figure 8 represents the data of lithium fluoride crystals irradiated with gold and xenon ions. The deduced track radius is between 1 and $2 \mathrm{~nm}$ and corresponds to the core radius in which complex defect aggregates are formed (Schwartz et al 1998; Trautmann et al 1998a).

\section{Chemical etching}

Another possibility to reveal the existence of ion tracks is the technique of selective chemical etching. Using a suitable etchant, the modified or damaged material along the ion track is dissolved at a faster rate than the bulk material. Although the ion track itself is destroyed, this technique still allows us to obtain specific information such as the number of tracks per unit surface area, orientation and geometry of the etched pores, and radiation sensitivity of the solid under study (Fleischer et al 1975).

In order to illustrate the diversity of chemical etching, etched pores in various materials are presented in figures 9-11.

Due to the sensitivity of polymers, an extremely high etching rate along the ion trajectory leads in many cases to almost cylindrical pores with a narrow pore size distribution (figure 9) (Trautmann et al 1996a).

Etching of tracks in LiF crystals results in pyramidal shaped etch pits illustrating that the chemical attack depends on the crystal orientation (figure 10) (Müller et al 1998; Trautmann et al 1998b).

Up to now, etchable tracks in metals have been wemonstrated only in a very special metal namely the glass-like iron boron alloy $\mathrm{Fe}_{81} \mathrm{~B}_{13.5} \mathrm{Si}_{3.5} \mathrm{C}_{2}$ (Trautmann

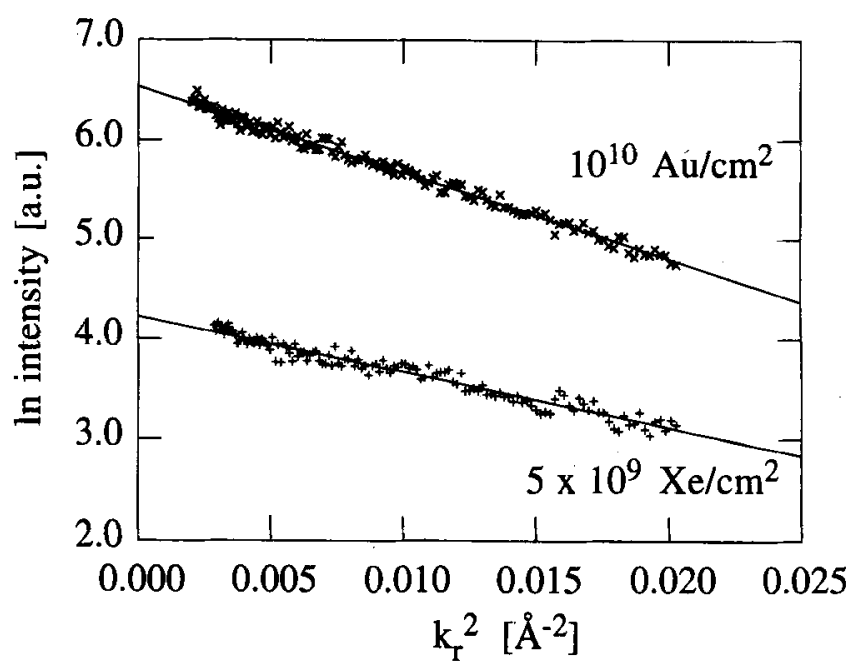

Figure 8. The logarithm of the scattered intensity as a function of the square of the scattering vector $k_{\mathrm{r}}$ for $\mathrm{LiF}$ crystals irradiated with $\mathrm{Xe}$ and $\mathrm{Au}$ ions (11.4 MeV/u) (Schwartz et al 1998). 
et al 1993a, 1996b, c). In this material, the resulting etch pits have wide opening angles (figure 11).

Successfull track etching is linked to a critical energy loss depending on the radiation sensitivity of a given material. For the $\mathrm{Fe}_{81} \mathrm{~B}_{13.5} \mathrm{Si}_{3.5} \mathrm{C}_{2}$ alloy, the critical energy loss for homogeneous track etching is around $3.4 \mathrm{keV} / \AA$ (figure 12) (Trautmann et al 1993b) which is rather high compared to the threshold of $0.4 \mathrm{keV} / \AA$ for tracks in polyimide (Trautmann et al 1996d).

\section{Applications}

Ion-induced material modifications, have been exploited and applied in many scientific and industrial applications

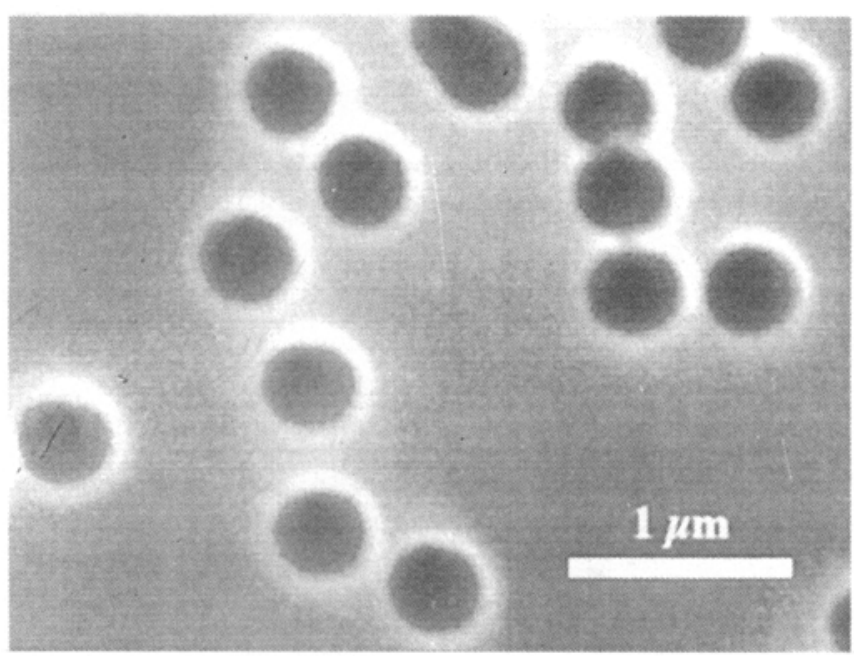

Figure 9. Cylindrical pores in polyimide (Trautmann et al 1996a).

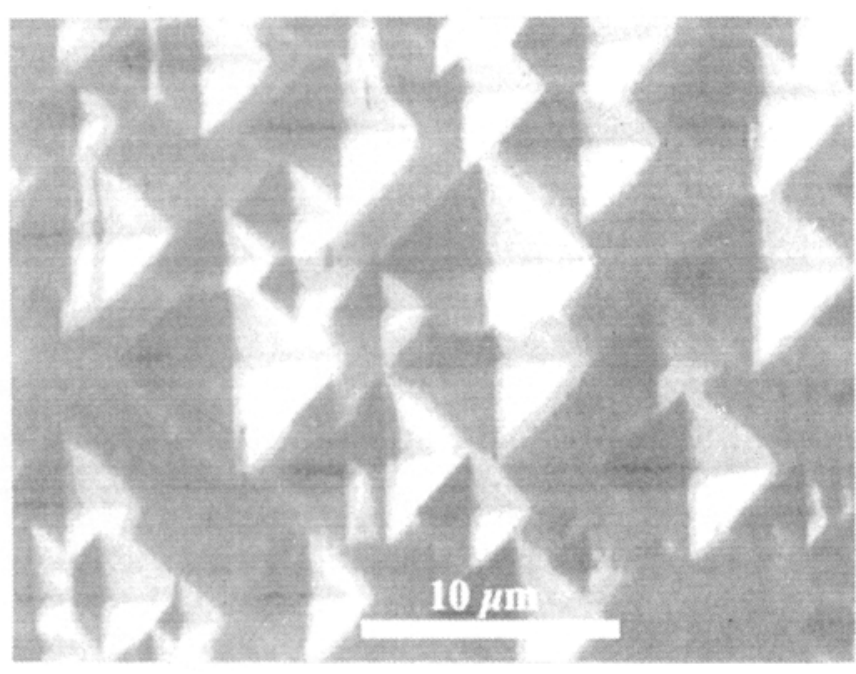

Figure 10. Pyramidal shaped etch pits in LiF (Trautmann et al 1998).
(Fleischer et al 1975, Spohr 1990). Big accelerators such as the UNILAC at the GSI in Darmstadt offer favourable conditions for the controlled generation of precise microstructures. In the following section, two selected examples are presented.

\subsection{Thermo-responsive membranes}

There has been a long tradition of using etched tracks in polymers as high precision membranes. More recently, the ion-track etch technique was combined with the field of hydrogels (Yoshida et al 1993). For this purpose, a thermo-responsive gel ( $\mathrm{N}$-isopropylacrylamide) was grafted onto the surface of an ion track filter (poly-

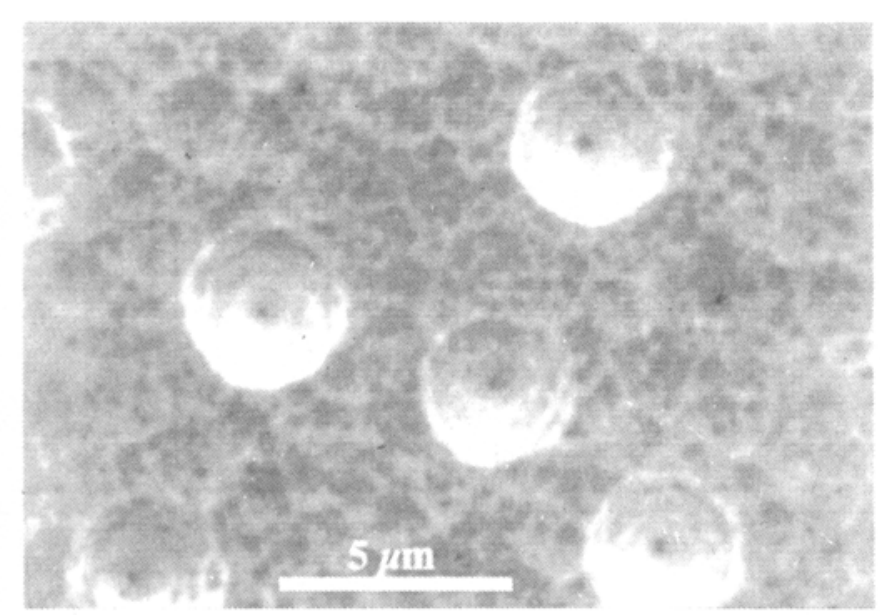

Figure 11. Conical surface pores of etched tracks in amorphous metal $\left(\mathrm{Fe}_{81} \mathrm{~B}_{13.5} \mathrm{Si}_{3.5} \mathrm{C}_{2}\right)$ (Trautmann et al 1993a).

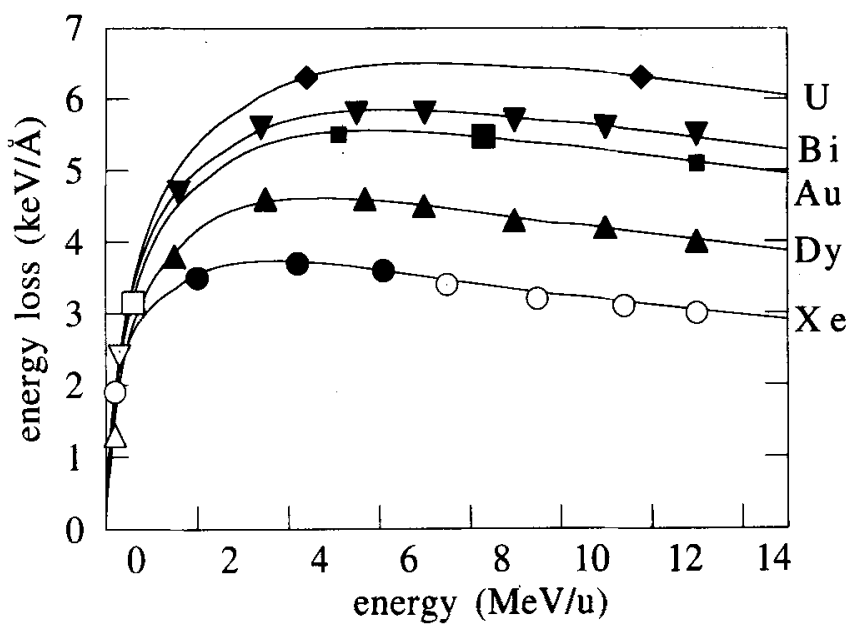

Figure 12. Curves of the energy loss as a function of the energy for various ion species (Ziegler et al 1985). Only in the case of filled symbols track etching in the amorphous metal is possible (Trautmann et al 1993b). 


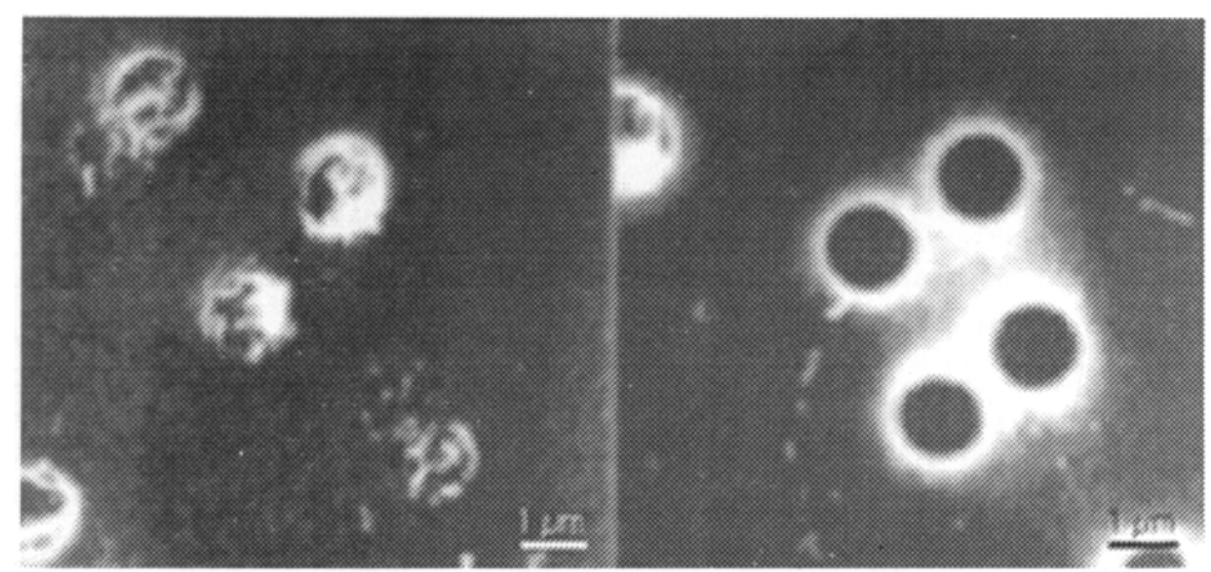

Figure 13. Transmission electron micrograph of pores in the swollen (left) and in the shrunken state (right) (Yoshida et al 1993).

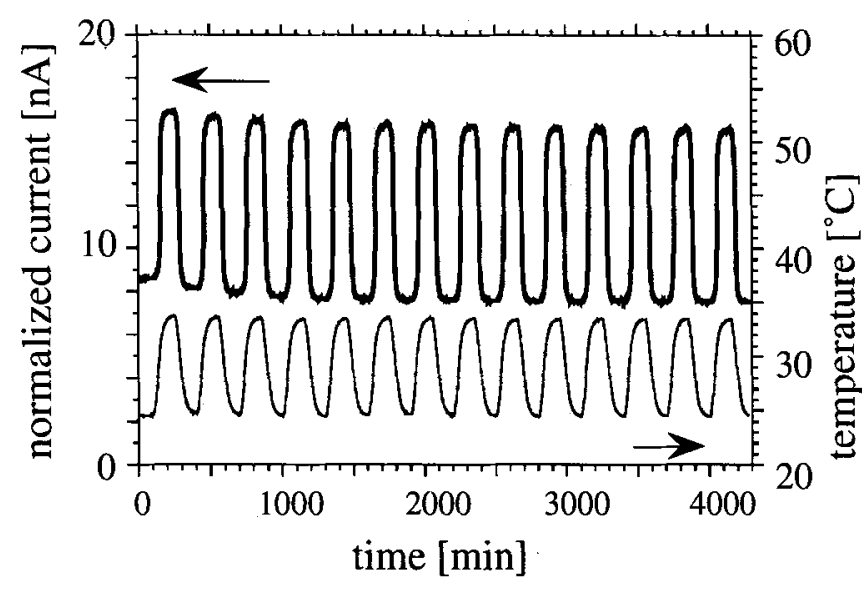

Figure 14. Continuous cycling of the temperature controlled opening and closing of a single responsive pore measured in a conductivity cell (Reber 1998).

ethylene-terephthalate). In an aqueous solution, such a membrane closes its pores below $31^{\circ} \mathrm{C}$ when the hydrogel swells significantly by taking up a large amount of water (figure 13). The flow of particles through the pores can be controlled by varying the temperature or $\mathrm{pH}$-value of the environment (Reber et al 1995; Tamada et al 1995; Yoshida et al 1996; Omichi et al 1997a, b; Yoshida et al 1997a, b; Hiroki et al 1998). Figure 14 shows the continuous cycling of the effective pore size as a function of the applied temperature, monitored by the flow of an electrolyte through the membrane (Reber et al 1998).

A variety of novel applications are expected from these responsive membranes including chemical valves, sensors or controlled drug delivery systems.

\subsection{Microstructures by replica technique}

Etched pores in polymers can also be used as templates for microgalvanic replication (Vetter and Spohr 1993).

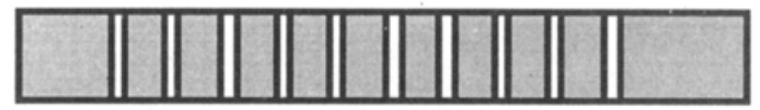

a) etched ion tracks in polymer

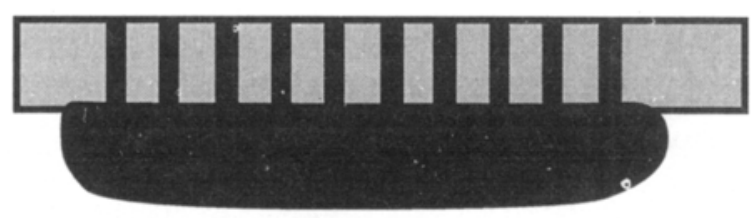

b) deposition of metal

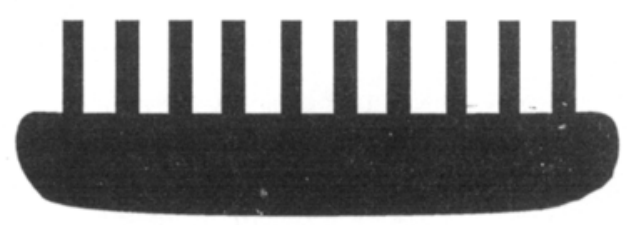

\section{c) dissolution of polymer}

Figure 15. Replica technique to produce metallic needles.

The principle of this technique is shown in figure $15 \mathrm{a}-\mathrm{c}$. In a galvanic process, the pores are filled with metallic material. In a subsequent step; the plastic material is removed in an organic solvent. Microstructures with an extremely large aspect ratio can be produced. Using suitable galvanic conditions, it is possible to obtain parallel or funnel shaped columns, hollow tubes, or tips from different metals. The deposition process can also be controlled in such a way that material is deposited as a single crystal (Vetter 1994; Dobrev 1998).

In combination with an ion microprobe (Fischer 1991), it was demonstrated that not only stochastically distributed 


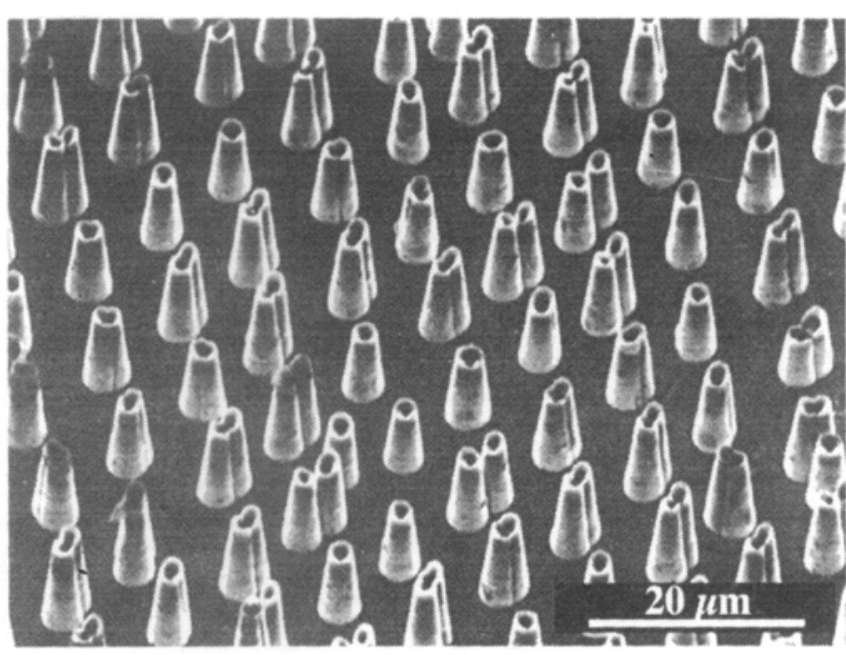

Figure 16. Microneedles replicated from a polycarbonate membrane with a regular ion track pattern.

but also ordered structures can be created (figure 16) (Vetter et al 1999).

\section{References}

Albrecht D, Armbruster P, Spohr R, Roth M, Schaupert K and Stuhrmann H 1985 Appl. Phys. A37 37

Albrecht D, Balanzat E and Schaupert K 1986 Nucl. Tracks Radiat. Meas. 1193

Barbu A, Dunlop A, Lesueur D and Averback R S 1991 Europhys. Lett. 1537

Biró L P, Gyulai J, Havancsak K, Didyk A Yu, Bogen S and Frey L 1996 Phys. Rev. B54 11853

Biró L P, Gyulai J and Havancsak K 1995 Phys. Rev. B52 2047

Bouffard S, Cousty J, Pennec Y and Thibaudau F 1993 Rad. Eff. Def. Solids 126225

Bourgault D, Bouffard S, Toulemonde M, Groult D, Provost J, Studer F, Nguyen N and Raveau B 1989a Phys. Rev. B39 6549

Bourgault D, Hervieu M, Bouffard S, Groult D and Raveau B 1989 Nucl. Instrum. Meth. B42 61

Bursill L A and Braunshausen G 1990 Philos. Mag. 62395

Coratger R, Claverie A, Ajustron F and Beauvillain J 1990 Surf. Sci. 2277

Dammak H, Dunlop A, Lesueur D, Brunelle A, Della-Negra S and Le Beyec Y 1995a Phys. Rev. Lett. 741135

Dammak H, Dunlop A and Beyec Y 1995 Phys. Rev. Lett. 74 1135

Dartyge E, Duraud J P, Langevin Y and Maurette M 1981 Phys. Rev. B23 5213

Dobrev D, Vetter J and Neumann R 1998 Nucl. Instrum. Meth. B146

Dunlop A, Jaskierowicz G, Jensen J and Della-Negra S 1997 Nucl. Instrum. Meth. 13293

Fischer B 1991 Nucl. Instrum. Meth. B54 401

Fleischer R L, Price P B and Walker R M 1965 Science 149 383
Fleischer R L 1998 in Tracks to innovation, Nuclear tracks in science and technology (New York: Springer)

Fleischer R L, Price P B and Walker R M 1975 Nuclear tracks in solids, Principles and applications (Berkeley: University of California Press)

Fuchs G, Studer F, Balanzat E, Groult D. Toulemonde $M$ and Jousset J C 1987 Europhys. Lett. 3321

Gervais B and Bouffard S 1994 Nucl. Instrum. Meth. B88 355

Hagen T, Grafström S, Ackermann J, Neumann R, Trautmann C, Vetter J and Angert N 1994 J. Vac. Sci. Technol. B12 1555

Henry J, Barbu A, Leridon B, Lesueur D and Dunlop A 1992 Nucl. Instrum. Meth. 67390

Hiroki A, Yoshida M, Yamashita J, Asano M, Reber N, Spohr R, Kumakura M and Katakai R 1998 J. Polym. Sci. A Polym. Chem. 361495

Houpert C, Hervieu M, Groult D, Studer F and Toulemonde M 1989a Nucl. Instrum. Meth. B32 393

Houpert C, Studer F, Groult D and Toulemonde M $1989 \mathrm{Nucl}$. Instrum. Meth. B39 720

Izui K and Fujita F E 1963 J. Jap. Phys. Soc. 18467

İui K and Suzuki A 1963 J. Jap. Phys. Soc. 18210

Katz R, Loh K S, Daling L and Huang G R 1990 Rad. Eff. Def. Solids. 11415

Kemmer H, Grafström S, Neitzert M, Wörtge M, Neumann R, Trautmann C, Vetter J and Angert N 1992 Ultramicroscopy 42-44 1345

Kraft G and Krämer M 1993 Adv. Rad. Biol. 171

Legris A, Fullier-Albenque F, Barbu A, Pascard H, Bouffard S, Paumier E and Lejay P 1993 Rad. Eff. Def. Solids 126 155

Meftah A et al 1994 Phys. Rev. B49 12457

Morgan D V and Chadderton L T 1968 Philos. Mag. 171135

Muller A, Neumann R, Schwartz K, Steckenreiter T and Trautmann C 1998 Appl. Phys. A66 S1147

Neumann R, Ackermann J, Angert N, Trautmann C, Dischner M, Hagen T and Sedlacek M 1996a Nucl. Instrum. Meth. B116 492

Omichi H et al 1997a Nucl. Instrum. Meth. B131 350

Omichi H et al 1997b J. Nucl. Mater. 248354

Porte L, Phaner $\mathrm{M}$, de Villeneuve $\mathrm{C} \mathrm{H}$, Moncoffre $\mathrm{N}$ and Tousset J 1989 Nucl. Instrum. Meth. B44 116

Porte L, de Villeneuve C H and Phaner M 1991 J. Vac. Sci. Technol. B9 1064

Ramos S M M, Bonardi N, Canut B and Della-Negra S 1998 Phys. Rev. B57 189

Reber N, Omichi H, Spohr R, Tamada M, Wolf A and Yoshida M 1995 Nucl. Instrum. Meth. B105 275

Reber N, Spohr R, Wolf A, Omichi H, Tamada M and Yoshida M 1998 J. Membrane Sci. 140275

Scholz R, Vetter J and Hoppe S 1993 Rad. Eff. Def. Solids 126275

Schwartz K, Trautmann C, Steckenreiter T, Geiss O and Krämer M 1998 Phys. Rev. B58 11232

Silk E C H and Barnes R S 1959 Philos. Mag. 4970

Spohr R 1990 lon tracks microtechnology, Basic principles and applications (Braun-Schweig: Vieweg)

Studer F, Houpert C, Pascard H, Spohr R, Vetter J, Fan J Y and Toulemonde M 1991 Rad. Eff. Def. Solids 11659

Tamada M, Asano M, Spohr R, Vetter J, Trautmann C, Yoshida 
M, Katakai R and Omichi H 1995 Macromol. Rapid Commun. 1647

Tang X, Yao J and Zhai P 1992 Nucl. Instrum. Meth. A320 369

Toulemonde M and Studer F 1988 Philos. Mag. 58799

Toulemonde M and Studer F 1993 Solid State Phenom. 30/31 477

Trautmann C, Andler S, Bruchle W, Spohr R and Toulemonde M 1993a Rad. Eff. Def. Solids 126207

Trautmann C, Spohr R and Toulemonde M 1993b Nucl. Instrum. Meth. B83 513

Trautmann C, Bruchle W, Spohr R, Vetter J and Angert N 1996a Nucl. Instrum. Meth. B111 70

Trautmann C, Dufour C, Paumier E, Spohr R and Toulemonde M 1996b Nucl. Instrum. Meth. B107 397

Trautmann C, Toulemonde M, Dufour C and Paumier E 1996c Nucl. Instrum. Meth. B108 94

Trautmann C, Bouffard S and Spohr R 1996d Nucl. Instrum. Meth. B116 429

Trautmann C, Schwartz K, Costantini J M, Steckenreiter T and Toulemonde M 1998a Nucl. Instr. Meth. Phys. Res. B146 367

Trautmann C, Schwartz K and Geiss O 1998b J. Appl. Phys. 833560

Vetter J 1994 Scanning 16118

Vetter J 1995 Rad. Meas. 2533

Vetter J and Spohr R 1993 Nucl. Instrum. Meth. B79 691
Vetter J, Scholz R and Angert N 1994 Nucl. Instrum. Meth. B91 129

Vetter J, Scholz R, Dobrev D and Nistor L 1998a Nucl. Instrum. Meth. B141 747

Vetter J, Ackermann J, Neumann R, Nistor L and Scholz R 1998b Advances in fission-track geochronology (eds) $\mathrm{P}$ Van den Haute and F De Corte (Dordrecht: Kluwer Academic Publishers) p. 3

Vetter J, Dobrev D, Fischer B and Metzger S 1999 Private communication

Wiesner J, Traeholt C, Wen J-G, Zandbergen H-W, Wirth G and Fuess H 1996 Physica C268 161

Yan J et al $1994 \mathrm{~J}$. Appl. Phys. 751390

Yoshida M, Tamada M, Asano M, Omichi H, Kubota H, Katakai R, Spohr R and Vetter J 1993 Rad. Eff. Def. Solids 126409

Yoshida M, Asano M, Safranj A, Omichi H, Spohr R, Vetter J and Katakai R 1996 Macromolecules 298987

Yoshida M et al 1997a Nucl. Instrum. Meth. B122 39

Yoshida M, Asano M, Omichi H, Spohr R and Katakai R 1997b Rad. Meas. 28799

Zhu Y, Cai Z X, Budhani R C, Suenaga M and Welch D O 1993 Phys. Rev. $\mathrm{B} 486436$

Ziegler J F, Biersack $P$ and Littmark $U 1985$ in The stopping and ranges of ions in matter (ed.) J F Ziegler (New York: Pergamon) 